\title{
Knowledge, Attitude and Practice of Parents regarding Feeding Pattern of Children
}

\author{
Nabeela Zia, Bushra Tariq, Ahsan Waheed Rathore, Arslan Ahmed Salam
}

\begin{abstract}
Objective: The objective was to determine the frequency of sufficient knowledge, positive attitude and good practice of parents about feeding pattern of children with malnutrition. Study Design: It was a Cross-Sectional Study. Settings: Department of Pediatric Medicine, Children Hospital Lahore Pakistan. Duration: Six-months i.e. December 1, 2018 to June 30, 2019. Methodology: Total of 385 children of both genders aged between 2-12 years who presented with malnutrition was enrolled. Demographic features of children and families were noted on a pre designed proforma. The parents were then assessed for their knowledge, attitude and practice about feeding through a structured questionnaire. A written informed consent was taken from parents of each child. Results: Of the total, $185(48.1 \%)$ were male and $200(51.9 \%)$ were female with mean age of $6.9 \pm 3.2$ years. Mean height and weight was $113.2 \pm 19.6 \mathrm{~cm}$ and $25.1 \pm 10.8 \mathrm{Kg}$ respectively. The number of children ranged from 1 to 5 with a mean of $2.7 \pm 1.3$ children per family. Thirty six percent $(n=141)$ were belonged to middle class, followed by lower class $(35.1 \%)$ and high class $(28.3 \%)$. Analysis showed that $228(59.2 \%)$ parents had sufficient knowledge, $209(54.3 \%)$ parents had positive attitude and only $152(39.5 \%)$ parents followed good practice. There was no association was seen between demographic characteristics and knowledge, attitude and practice (KAPs) of parents. Conclusion: This study showed that sufficient positive attitude, knowledge and good feeding practice in more or less half of the parents with malnourished children which is alarming and warrants public health measures in this regard to address these issues which might result in reduction of child's malnutrition along with its associated morbidity and mortality.
\end{abstract}

Keywords: Malnutrition, Parent's feeding practice, Knowledge, Attitude.

Corresponding Author

Submitted for Publication: 23-01-2020

Accepted for Publication: 26-02-2020

DR. NABEELA ZIA, Senior Registrar, Department of Pediatric Medicine, The Children's Hospital and Institute of Child Health Lahore-Pakistan.

Contact / Email: +92 321-6428327, nabeelazia@gmail.com

Citation: Zia N, Tariq B, Rathore AW, Salam AA. Knowledge, Attitude and Practice of Parents Regarding Feeding Pattern of Children. APMC 2020;14(1):74-7.

\section{INTRODUCTION}

Eating behaviors evolve in infancy because biological and behavioral processes are directly linked with the health and growth. In human history, food scarcity is a major threat for existence resulting in evolving of eating behavior and child feeding practices. Generally during scarcity, the family life and resources are concerted for the procurement and availability of foods leading to low in energy, palatability and nutrients. 1,2 It has been reported that this behavioral change is the modifiable etiology of weight problems. It has been reported that eating behavior and appetite-related traits of the children are directly associated with their BMI.

The role of parents has also been reported as an important influence on eating behaviors of children. ${ }^{3}$ Child diet and weight are directly linked with the food practices and eating habits of their parents. Similarly, these practices have great influence on children's food intake which have been measured using different instruments. ${ }^{4,5}$

Role of parents in developing good or bad children's dietary habits is well established. Various public health interventions have designed focusing the parents to improve children's diets. This eventually helped in reducing overall prevalence of obesity and malnutrition during childhood. 2,6,7 According to a previous study done in Australia, the percentage of sufficient knowledge, positive attitude and good practice about feeding patterns is $54 \%, 99 \%$ and $92 \%$ respectively. ${ }^{8}$
Different studies have been conducted regarding attitude, knowledge and practice of parents about feeding pattern of children and weight of child. But no study contained the percentage of KAPs of parents regarding feeding pattern of their children. So, the rationale of this study is to determine the KAPs of parents regarding feeding pattern of children coming at Children Hospital, Lahore.

\section{METHODOLOGY}

Study Design: It was a Cross-Sectional Study.

Settings: Pediatric Medical Wards and Emergency Department of The Children Hospital and The Institute of Child Health Lahore-Pakistan.

Duration: Period of 6 months ranging from December 1, 2018 to June 30, 2019.

Sample Technique: Non-probability consecutive sampling technique.

Sample Size: Sample size of 385 parents was calculated 95\% confidence level and with 5\% margin of error and assuming percentage of sufficient knowledge i.e. $54 \%$ about child's feeding pattern.

Inclusion Criteria: Parents with children of age 2-12 years of either gender presenting with malnutrition (as per operational definition) were included in the study.

Exclusion Criteria: Parents could not understand local language and children with eating disorder (on history) were excluded from the study. 
Data Collection: Children fulfilling the selection criteria were enrolled from OPD at Children Hospital and The Institute of Child Health, Lahore after taking informed consent from parents. Demographics (including name, age, sex, weight, height) were recorded. Then parents were asked about the feeding pattern of their children. Questions regarding, Knowledge, attitude and practice of were asked from parents as per questions already designed in proforma. Sufficient knowledge, positive attitude and good practice of parents were noted (as per operational definition). All this information was recorded through proforma (attached).

Data Analysis: Data was entered, cleaned and analyzed through SPSS version 20.0. Numerical variables were taken age, weight and height have been presented by mean \pm SD. Whereas, categorical variable i.e. gender, number of children per family, sufficient knowledge, positive attitude and good practice has been presented by frequency and percentage. Data has been stratified for age, gender, weight, height of child, number of children of a particular couple, education level of parents, parent's current age and socioeconomic status. Chisquare test was used for post-stratification association. A pvalue $\leq 0.05$ was considered as significant.

\section{RESULTS}

Of total 385 enrolled children, 185 (48.1\%) male and 200 $(51.9 \%)$ were female children. The height and weight of children was $113.2 \pm 19.6$ (80 to 150) $\mathrm{cm}$ and $25.1 \pm 10.8$ (8 to 43 ) $\mathrm{Kg}$. Educational status of the parent showed that $33.8 \%$ fathers and $183(47.6 \%)$ mothers were illiterate. About a quarter $(n=141$, $36.6 \%$ ) were belonging to middle class followed by lower class (35.1\%) and high class (28.3\%). More than fifty percent (59.2\%) parents had sufficient knowledge feeding of the children while $54.3 \%$ parents had positive attitude. However, $39.5 \%$ parents followed good practice.

Analysis showed that knowledge, attitude and practice have no association with different demographic features including age, gender, literacy, socio economic status of the parents (Tables).

Table: Association of Demographics with Knowledge Attitude and Practices (KAPs)

\begin{tabular}{|c|c|c|c|c|}
\hline Subgroups & $\mathbf{N}$ & Sufficient Knowledge ( $n=228$ ) & Positive Attitude ( $n=209$ ) & Good Practice $(n=152)$ \\
\hline \multicolumn{5}{|c|}{ Father's Age (years) } \\
\hline 28-37 years & 194 & $118(60.8 \%)$ & $110(6.7 \%)$ & $84(43.3 \%)$ \\
\hline $38-47$ years & 191 & $110(57.6 \%)$ & $99(51.8 \%)$ & $68(35.6 \%)$ \\
\hline P Value & & 0.519 & 0.338 & 0.122 \\
\hline \multicolumn{5}{|c|}{ Mother's Age (years) } \\
\hline $22-30$ years & 230 & $140(60.9 \%)$ & $127(5.2 \%)$ & $98(42.6 \%)$ \\
\hline $31-38$ years & 155 & $88(56.8 \%)$ & $82(52.9 \%)$ & $54(34.8 \%)$ \\
\hline P Value & & 0.423 & 0.655 & 0.126 \\
\hline \multicolumn{5}{|l|}{ Father's Education } \\
\hline Illiterate & 130 & $75(57.7 \%)$ & $72(55.4 \%)$ & $49(37.7 \%)$ \\
\hline Under Matric & 141 & $79(56.0 \%)$ & $70(49.6 \%)$ & $57(40.4 \%)$ \\
\hline Matric and above & 114 & $74(64.9 \%)$ & $67(58.8 \%)$ & $46(40.4 \%)$ \\
\hline$P$ Value & & 0.325 & 0.331 & 0.877 \\
\hline \multicolumn{5}{|c|}{ Mother's Education } \\
\hline Illiterate & 183 & $105(57.4 \%)$ & $100(54.6 \%)$ & $75(41.0 \%)$ \\
\hline Under Matric & 101 & $61(60.4 \%)$ & $54(53.5 \%)$ & $43(42.6 \%)$ \\
\hline Matric and above & 101 & $62(61.4 \%)$ & $55(54.5 \%)$ & $34(33.7 \%)$ \\
\hline P Value & & 0.774 & 0.981 & 0.336 \\
\hline \multicolumn{5}{|c|}{ No. of Siblings per Family } \\
\hline $1-2$ & 185 & $112(60.5 \%)$ & $95(51.4 \%)$ & $69(37.3 \%)$ \\
\hline $3-5$ & 200 & $116(58.0 \%)$ & $114(57.0 \%)$ & $83(41.5 \%)$ \\
\hline$P$ value & & 0.612 & 0.266 & 0.339 \\
\hline \multicolumn{5}{|c|}{ Socio-economic Status } \\
\hline Lower Class & 135 & $79(58.5 \%)$ & $68(50.4 \%)$ & $57(42.2 \%)$ \\
\hline Middle Class & 141 & $84(59.6 \%)$ & $80(56.7 \%)$ & $53(37.6 \%)$ \\
\hline High Class & 109 & $65(59.6 \%)$ & $61(56.0 \%)$ & $42(38.5 \%)$ \\
\hline P Value & & 0.979 & 0.522 & 0.713 \\
\hline
\end{tabular}

Chi-square test, observed difference was statistically insignificant 


\section{DISCUSSION}

Overall, $26 \%$ children in the world under five years age are living in South Asia. Around 38\% have stunting which is an outcome of biological and/or psychosocial deprivation in early age. This results into multiple health and societal issues. ${ }^{9-10}$ The global impact of childhood malnutrition is staggering.

By using appropriate preventive interventions for malnutrition, we can prevent $61 \%$ cases of wasting and save the lives of almost 350,000 child deaths annually. Various key international initiatives including No Wasted Lives are working hard to achieve these ambitious targets. ${ }^{11}$

Parent food practices and feeding style influence child diet and/or weight and contribute to the development of under nutrition or malnutrition. ${ }^{8}$

Our study showed that $59.2 \%$ parents had sufficient knowledge, $209(54.3 \%)$ parents had positive attitude but only $39.5 \%$ followed good practice. Our results are comparable to those of Tan et al. ${ }^{12}$ (2010) who reported similar frequency of sufficient knowledge (52.2\%), positive attitude $(56.9 \%)$ and good practice (37.7\%) among non-parent caregivers in rural China. Mehrabani et al. ${ }^{13}$ (2009) in another similar study involving families from Tehran reported comparable frequency of sufficient knowledge (59.6\%), positive attitude $(60.8 \%)$ and good practice $(33.8 \%)$ in children with malnutrition. Oli et al. ${ }^{14}$ (2018) observed comparable frequency of sufficient knowledge and positive attitude in Nepalese families and reported to be $58.1 \%$ and $44.6 \%$ respectively. Moaadeli et al. ${ }^{15}(2015)$ and Lombardi et al. ${ }^{8}$ (2013) reported comparable frequency of $61.5 \%$ and $54.0 \%$ respectively for sufficient knowledge in parents with malnourished children.

Child malnutrition is common in Pakistan and ranked among the countries having highest rate in the world. It has been shown that progress in child nutrition and health remained slower as compared to other South Asian countries. ${ }^{16}$ The National Nutrition Survey (NNS) 2011 showed that there had been no major improvement in last ten years in terms of childhood nutrition indicators. In 2011, the percentage of children under five-year age with stunting and wasting $44 \%$ and $15 \%$ which was almost similar of 2001 i.e. $41 \%$ and $14 \%$ respectively. Similarly, no change has been seen in percentage of underweight from 2001 to $2011 .{ }^{17}$

In the present study, we observed sufficient knowledge, positive attitude and good feeding practice in more or less half of the parents with malnutrition children which is alarming and warrants public health measures in this regard to address these issues which might result in reduction of child's malnutrition along with its associated morbidity and mortality.

In the present study we found that none of the socio demographic factor of the parents affected sufficient knowledge, positive attitude and good feeding practice significantly; establishing independent nature of these parameters. In order to reduce child malnutrition, the interventions must target both all societal elements including both rich and poor, young and the old, male and female alike.
CONCLUSION

Though parents have sufficient knowledge and positive attitude but their practices are not and good feeding practice in more or less half of the parents with malnourished children which is alarming and warrants public health measures in this regard to address these issues which might result in reduction of child's malnutrition along with its associated morbidity and mortality.

\section{LIMITATIONS}

There are some potential limitations that we didn't compare the parent's knowledge, attitude and feeding practice with control group i.e. children without malnutrition which could have enabled estimation of relative risk.

\section{SUGGESTIONS / RECOMMENDATIONS}

Such a study is highly recommended in future research. Moreover, there is need for a study addressing effect of intervention in the form of parent's education about feeding practice upon child's nutritional status which would help in policy making and strategic planning to decrease the likelihood of malnutrition.

\section{CONFLICT OF INTEREST / DISCLOSURE}

No conflict of interest is involved.

\section{ACKNOWLEDGEMENTS}

We are thankful to the staff of Department of Pediatric Medicine, The Children's Hospital and Institute of Child Health Lahore Pakistan for their cooperation in data collection.

\section{REFERENCES}

1. Scaglioni S, Arrizza C, Vecchi F, Tedeschi S. Determinants of children's eating behavior. Am J Clin Nutr. 2011;94(6):2006-11.

2. Schwartz C, Scholtens PA, Lalanne A, Weenen H, Nicklaus S. Development of healthy eating habits early in life. Review of recent evidence and selected guidelines. Appetite. 2011;57(3):796-807.

3. Jansen PW, Roza SJ, Jaddoe VW, Mackenbach JD, Raat H, Hofman A, et al. Children's eating behavior, feeding practices of parents and weight problems in early childhood: results from the population-based Generation R Study. Int J Behav Nutr Phys Act. 2012;9(1):130.

4. Blissett J. Relationships between parenting style, feeding style and feeding practices and fruit and vegetable consumption in early childhood. Appetite 2011;57(3):826-31.

5. Vaughn AE, Tabak RG, Bryant MJ, Ward DS. Measuring parent food practices: a systematic review of existing measures and examination of instruments. Int J Behav Nutr Phys Act. 2013;10(1):61.

6. Dattilo AM, Birch L, Krebs NF, Lake A, Taveras EM, Saavedra JM. Need for early interventions in the prevention of pediatric overweight: a review and upcoming directions. J Obes. 2012;2012:3659.

7. Mitchell GL, Farrow C, Haycraft E, Meyer C. Parental influences on children's eating behavior and characteristics of successful parent-focussed interventions. Appetite 2013;60(1):85-94.

8. Lombardi K. Self -efficiency and nutrition knowledge of parents in western Australia. 2013. http://ro.ecu.edu.au/theses_hons/107. 
9. Stewart CP, lannotti L, Dewey KG, Michaelsen KF, Onyango AW. Contextualising complementary feeding in a broader framework for stunting prevention. Matern Child Nutr. 2013;9(2):27-45.

10. De Onis M, Dewey KG, Borghi E, Onyango AW, Blossner M, Daelmans B, et al. The World Health Organization's global target for reducing childhood stunting by 2025: rationale and proposed actions. MaternChild Nutr. 2013;9(2):6-26.

11. Bhutta ZA, Berkley JA, Bandsma RHJ, Kerac M, Trehan I, Briend A. Severe childhood malnutrition. Nat Rev Dis Primers. 2017;3:17067.

12. Tan C, Luo J, Zong R, Fu C, Zhang L, Mou J, et al.Nutrition knowledge, attitudes, behaviors and the influencing factors among non-parent caregivers of rural left-behind children under 7 years old in China. Public Health Nutr. 2010;13(10):1663-8.

13. Mehrabani $H$, Mirmiranl $P$, Alaiin F, Azizi FE. Changes in nutritional knowledge, attitude, and practices of adolescents in district 13 of Tehran after 4 years of education. Iran J Endocrinol Metabol 2009;11(3):235-43.

14. Oli N, Vaidya A, Pahkala K, Eiben G, Krettek A. Knowledge, attitude and practice on diet and physical activity among mothers with young children in the Jhaukhel-Duwakot Health Demographic Surveillance Site, Nepal. PLoS ONE 2018;13(7):e0200329.

15. Moaadeli Z, Neyrizi AH, Sharifikia I, Marandi KA. The study of knowledge, attitude and nutritional practice of secondary school students in Darab city, Fars province, Iran in 2011-2012. Int J School Health. 2015;2(2):e25702.

16. Bhutta ZA, Hafeez A, Rizvi A, Ali N, Khan A, Ahmad F, et al. Reproductive, maternal, newborn, and child health in Pakistan: challenges and opportunities. Lancet 2013;381(9884):2207-18.

17. National Nutrition Survey 2011. Planning Commission, Planning \& Development Division, Government of Pakistan. 2011

\section{AUTHORSHIP AND CONTRIBUTION DECLARATION}

AUTHORS
$\begin{aligned} & \text { Dr. Nabeela Zia } \\ & \text { Senior Registrar, Department of Pediatric Medicine, } \\ & \text { The Children's Hospital and Institute of Child Health } \\ & \text { Lahore Pakistan }\end{aligned}$
$\begin{aligned} & \text { Dr. Bushra Tariq } \\ & \text { Registrar, Department of Pediatric Medicine, The } \\ & \text { Children's Hospital and Institute of Child Health } \\ & \text { Lahore Pakistan }\end{aligned}$
$\begin{aligned} & \text { Dr. Ahsan Waheed Rathore } \\ & \text { Professor of Pediatrics, Department of Pediatric } \\ & \text { Medicine, The Children's Hospital and Institute of } \\ & \text { Child Health Lahore Pakistan }\end{aligned}$
$\begin{aligned} & \text { Arslan Ahmed Salam } \\ & \text { Research Officer, Pakistan Health Research } \\ & \text { Council, (PHRC) Islamabad Pakistan }\end{aligned}$

